Dear Sir

The reactions of Dr Dally are predictably those of many modern psychiatrists.

There is, of course, a need for vigorous debate, but the issue is not whether community psychiatry can 'transmogrify' psychiatric disorder and create 'good responsible citizens' in the community - but whether a proportion of psychiatric resources can usefully be deployed therein.

My view is that they can, because as psychiatrists we should have something useful to offer, and because by such experiences we will improve our understanding of how psychiatric problems develop in the community, thus enhancing the quality of our work within the hospital, our ability to train future GPs and in time our understanding of preventive psychiatric measures.

The 'secret therapeutic weapon' is what I regard as skills that are basic to a psychiatrist - the ability to understand why people feel as they do, and the ability to help them understand themselves and each other better.

Dr Dally dismisses the idea of 'facilitating communication' between the variety of primary care agencies as euphemistic. Perhaps he has never attempted such work and so fails to grasp its importance in society.

I wonder whether concepts such as psychotherapy, brief crisis intervention and individual and family counselling are what he regards as 'verbiage'? If so, this strengthens my concern that modern psychiatrists are trained simply to make diagnoses, prescribe drugs and little else. They should not be surprised to find 'such little faith in psychiatric efficiency'.

As for the schools, is Dr Dally really prepared to leave our adolescents to the minister, the Chief Girl Guide and Mrs Woodhouse (Whitehouse, I think he means).

Like him, I am unsure of my effectiveness in such ventures, but cannot ignore the strong request for help from teaching staff, not only for social education programmes but also to discuss issues of adolescent behaviour and mental health in schools. If this helps teachers themselves to cope better with their professional roles, then this is sufficient justification in such work for me.

Finally, Dr C. M. Corser's letter (Bulletin, March 1982, 6, 46) reminds us of his successful experiment in Livingston with primary care teams. Such work plays a valuable part in community psychiatry and has a similar target patient population to my own. Our main difference of emphasis lies in the interpretation of 'appropriate psychiatric role' not only with the network of community support systems but also with general practitioners.

The debate about community psychiatry and appropriate psychiatric role is long overdue. If we are to handle more effectively the large psychiatric morbidity in the general population such questions must be raised and given high priority by more members of the medical profession and by the respective Colleges of Psychiatrists and General Practitioners.

Royal Edinburgh Hospital

JUDY GREENWOOD

Morningside Terrace, Edinburgh

\section{Aubrey Lewis's education}

\section{DEAR SIR}

I do have some hesitation in writing to you with a correction of such a distinguished psychiatrist as Dr Eliot Slater. I am given some courage by the footnote at the bottom of the second part of the article 'In conversation with Eliot Slater' on page 178 of the Bulletin, October 1981.

The point of correction is that Sir Aubrey Lewis was educated, not by the Jesuits as Dr Slater suggests, but by the Irish Christian Brothers at Christian Brothers College, Wakefield Street, Adelaide. To my knowledge the Jesuits were not represented in Adelaide, certainly not in the educational sphere, at that time.

My informant is Mr Eric Heenan (Senior), a retired solicitor and state parliamentarian of Perth, Western Australia, who attended school at CBC Wakefield Street with Aubrey Lewis. Mr Heenan's recollections of Lewis are of an intellectual stature which left his school mates sometimes astounded. He attended the school as a day boy and made a big impression by leaving for home immediately school finished, in particular avoiding sporting activities. It was rumoured in the school that his father disallowed any sporting activities because they might interfere with his studies to which he was expected to apply himself in all spare moments.

Nevertheless I am sure Lewis would have become quite familiar with the Catholic sub-culture of the Englishspeaking world under the Christian Brothers, even if he was kept away from sport which was, of course, a very important part of that sub-culture in Australia.

Royal Perth Hospital

PAul W. SKerrmt

Perth, Western Australia 6001 